\title{
Assessment of the Knowledge, Attitudes and Perception of Potential Occupational Hazards by Automobile Workers in Makurdi, Benue State, Nigeria
}

\author{
Olaiya Paul Abiodun ${ }^{1}$, Samson Olusegun Aturaka ${ }^{2}$, Okareh Oladapo ${ }^{3}$, Justin Nwofe ${ }^{4}$, \\ Abiodun Abiola ${ }^{5}$, Omotola Olushola ${ }^{6}$, Omotola Teniola ${ }^{6}$ \\ ${ }^{1}$ Department of Public Health, Central University of Nicaragua, Guyana, South America \\ ${ }^{2}$ Department of Public Health, Texila American University, Guyana, South America \\ ${ }^{3}$ Department of Environmental Health Sciences, Faculty of Public Health, College of Medicine, University of Ibadan, Ibadan, Nigeria \\ ${ }^{4}$ Department of Public Health, University of South Wale, Wales, United Kingdom \\ ${ }^{5}$ Department of Medical Laboratory Services, Benue State University, Makurdi, Nigeria \\ ${ }^{6}$ Department of Health and Applied Sciences, University of the West of England, Bristol, United Kingdom
}

\section{Email address:}

drabiodunolaiya@gmail.com (O. P.Abiodun), segunhydd@yahoo.com (S. O. Aturaka), dapsy2001@yahoo.co.uk (O. Oladapo), jnwofe@ahninigeria.org (J. Nwofe), abiola4real04@yahoo.com (A. Abiola), dasholi@outlook.com (O. Omotola), dasholi@outlook.com (O. Teniola)

\section{To cite this article:}

Olaiya Paul Abiodun, Samson Olusegun Aturaka, Okareh Oladapo, Justin Nwofe, Abiodun Abiola, Omotola Olushola, Omotola Teniola. Assessment of the Knowledge, Attitudes and Perception of Potential Occupational Hazards by Automobile Workers in Makurdi, Benue State, Nigeria. American Journal of Health Research. Vol. 6, No. 2, 2018, pp. 37-43. doi: 10.11648/j.ajhr.20180602.11

Received: October 25, 2017; Accepted: January 6, 2018; Published: March 15, 2018

\begin{abstract}
The objective of this study is to assess the knowledge and perception of Automobile workers on the occupational hazards in their workplaces and to identify their attitudes and safety practices towards protecting themselves from these hazards. A descriptive cross- sectional design and stratified sampling technique were utilized to identify the automobile workers/respondents. A structured questionnaire was used for data collection and it covered areas like social demographics, knowledge and perception of potential hazards, attitude and safety practices employed by both Automobile Mechanics (AMs) and Automobile Spray Painters (ASPs) to avoid hazards. The data collected was analyzed using SPSS version 21. Findings showed that there was statistically significant association between level of knowledge, attitude, perception of spray painters and mechanics based on their level of education. Also there was statistically significant association between level of knowledge, attitude, perception of spray painters and mechanics based on their work experience in relation to safety measures $(\mathrm{p}<0.05)$. However, there was no statistical significant difference in the knowledge of spray painters and mechanics about PPE as it can be generally rated poor $(<50 \%), \mathrm{P}>0.05)$. The $\mathrm{p}$ value for each of the tested parameter $(>0.05)$ also shows clearly that there was no significant difference in the knowledge of both the Automobile spray printer and the Mechanics. There is need for regular training on safety guidelines and enforcement of standard/universal safety practices by automobile workers so as to reduce potential occupational hazards.
\end{abstract}

Keywords: Personal Protective Equipment (PPE), Automobile Mechanics (AMs), Automobile Spray Painters (ASPs)

\section{Introduction}

The cost of labor is very cheap and this is due level of poverty is high in developing countries such as Nigeria. Proper occupational hygiene and pollution control methods are often neglected at worksites [1]. The garage operators also known as Automobile Mechanics (AMs) and Automobile Spray Painters (ASPs) are low-income earners with little or no basic education and limited knowledge of modern technology to operate effectively [2]. Automobile 
workshop workers are a class of labor considered to be prone to long-term lead toxicity due to their routine works such as motor vehicle assembly, spray painting, burning of petrol, welding, brazing and repairing of radiators [3]. In Nigeria, there is lack of sufficient safety information and safety magazines and/or pamphlets [4]. Personal protective equipment are usually considered a luxury and rarely provided and it is worse among the small factory workers [1].

In Modern societies like Nigeria, automobiles are considered as an integral part which are known as the source of environmental contaminants that are very toxic to humans [5].

AMs and ASPs which are also known as are required to apply chemicals which can be hazardous to human health in order perform repairs on vehicles. The application of chemicals used are typically involves the spraying of aerosolized agents onto a part or surface of car [6]. The spraying of commonly used chemicals such as Nitrocellulose thinner, Polyisocyanates and other hydrocarbons are the most effective means of applying solvents, penetrating lubricants and cleaners to often oddly shaped or difficult to reach parts of a vehicle [7]. Ironically, the ease of application for these chemicals is that they become airborne and can easily be inhaled into the respiratory system [8]. Although different individuals have different sensitivity, reactivity and irritation levels to the chemicals, even at low concentrations, many solvents and solids in paints have specific threshold limit values (TLVs) [NIOSH., 1978]., thus different exposure values and guidelines require controlled exposure monitoring to establish the appropriate and effective protection methods [9].

Conducting a survey study on the knowledge and perception of Automobile workers on the occupational hazards in their workplaces and to identify their attitudes and safety practices towards protecting themselves from these hazards will not be out of place in order to unravel salient information, whether there is a need for improvement on the modules operandi of the automobile activities in the state. Hence this study was intended to bridge this gap of knowledge regarding the practices in Makurdi Local Government, Benue State, Nigeria. It will serve as a strong compass to guide in the next line of action for all stakeholders involved in automobile practices.

\section{Methods}

This study is a cross-sectional survey study. Data was obtained through administering questionnaire on the automobile workers, after a due pilot study was conducted with it, and appraised by the erudite researchers. Six research assistants from Makurdi Local government and Hospital management boards were trained on how to administer the questionnaire and were fully involved in the data collection process. Data were analyzed using descriptive statistics of frequencies, percentages, and pie charts. Inferential statistics of Chi-square was used to test for significant associations between socio-demographic variables and the practices of the automobile workers, and their perception on the chemicalshydrocarbons frequently used in general.

The scoring of section was based on the answer ticked and was rated with points as strongly agree-5, agree-4, not sure-3, disagree-2, strongly disagree- 1 . The total score in percent will be rated good, moderate or poor. A respondent that scored $75 \%$ and above will be rated good, those that scored between $50 \%$ $74 \%$ will be rated moderate and below $50 \%$ will be rated poor. Statistical level of significance was set at $\mathrm{P}$-value $<0.05$.

\section{Results}

A total of One Hundred and Seventeen (117) respondents were interviewed out of which One Hundred and five (105) questionnaires were recovered giving a response rate of $90 \%$. SOCIO-DEMOGRAPHIC DATA

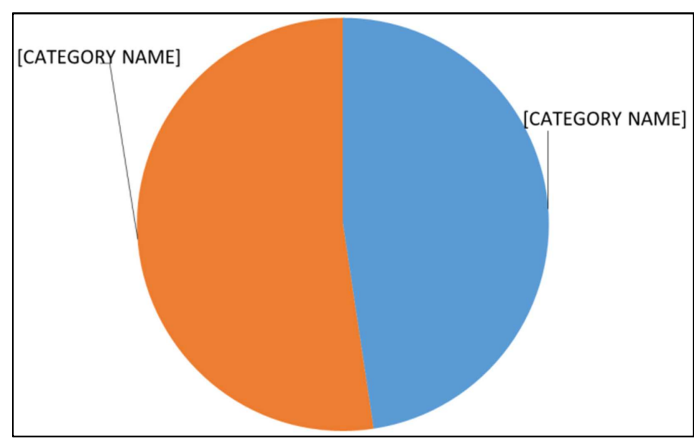

Figure 1. Occupation of Automobile workers.

Table 1. Socio-demographic Parameters of Automobile workers.

\begin{tabular}{|c|c|c|c|c|}
\hline & & OCCUPATION & & \\
\hline \multirow[t]{2}{*}{ Parameters } & & Automobile Spray Painters $(n=50)$ & Mechanics $(n=55)$ & Total $(n=105)$ \\
\hline & & Number (\%) & Number (\%) & Number (\%) \\
\hline \multirow{3}{*}{ Marital status } & Single & $12(24.0 \%)$ & $6(10.9 \%)$ & $18(17.1 \%)$ \\
\hline & Married & $34(68.0 \%)$ & $47(85.5 \%)$ & $81(77.1 \%)$ \\
\hline & Separated & $4(4.0 \%)$ & $2(2.6 \%)$ & $6(5.8 \%)$ \\
\hline \multirow{2}{*}{ Religion } & Christianity & $30(60.0 \%)$ & $36(65.5 \%)$ & $66(62.9 \%)$ \\
\hline & Islam & $20(40.0 \%)$ & $19(34.5 \%)$ & $39(37.1 \%)$ \\
\hline \multirow{4}{*}{ Level of education } & Primary & $7(14.0 \%)$ & $5(9.1 \%)$ & $12(11.4 \%)$ \\
\hline & Secondary & $17(34.0 \%)$ & $13(23.6 \%)$ & $30(28.6 \%)$ \\
\hline & Diploma & $1(2.0 \%)$ & $8(14.5 \%)$ & $9(8.6 \%)$ \\
\hline & First Degree & $2(4.0 \%)$ & $1(1.8 \%)$ & $3(2.9 \%)$ \\
\hline \multirow{3}{*}{ Time Spent in work } & $1-2$ years & $2(4.0 \%)$ & $4(7.3 \%)$ & $6(5.7 \%)$ \\
\hline & $3-5$ years & $10(20.0 \%)$ & $11(20.0 \%)$ & $21(20 \%)$ \\
\hline & $>5$ years & $38(76.0 \%)$ & $40(72.7 \%)$ & $78(74.5 \%)$ \\
\hline
\end{tabular}


Most of the respondents were married 81 (77.1\%), followed by $18(17.1 \%)$ for single, $6(5.8 \%)$ for separated while none was divorced or widowed.

Table 2. Age category.

\begin{tabular}{lll}
\hline Age Group & Frequency & Percent \\
\hline $20 \&$ below & 3 & 2.9 \\
$21-30$ & 25 & 23.8 \\
$31-40$ & 35 & 33.3 \\
$41-50$ & 19 & 18.1 \\
$51-60$ & 14 & 13.3 \\
Above 60 & 9 & 8.6 \\
Total & 105 & 100.0 \\
\hline
\end{tabular}

The minimum age (in years) of the respondents was 19 and the maximum was 72 with the most frequent age being 35 while the median and the mean ages were 38 and $40 \pm 13$ respectively.

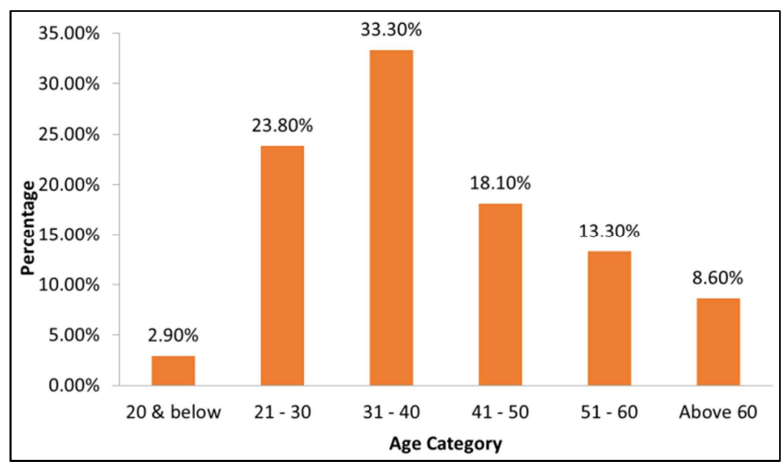

Figure 2. Age Category

Table 4. Knowledge of components/ingredients of used chemicals by occupation.

\begin{tabular}{|c|c|c|c|c|c|}
\hline \multirow{3}{*}{ Question } & \multicolumn{5}{|l|}{ Occupation } \\
\hline & \multirow{2}{*}{ Response } & Automobile Spray Painters & Mechanics & \multirow{2}{*}{ Total (\%) } & \multirow{2}{*}{$\mathbf{p}$} \\
\hline & & Number (\%) & Number (\%) & & \\
\hline Do you know the components/ingredients & Yes & $13(26.0 \%)$ & $14(25.5 \%$ & $27(25.7 \%)$ & 0.949 \\
\hline \multirow[t]{2}{*}{ If yes, do you know the effects } & Yes & $7(14.0 \%)$ & $11(20.0 \%)$ & $18(17.1 \%)$ & 0.415 \\
\hline & Cough & $3(6.0 \%)$ & $3(5.5 \%)$ & $6(33.3 \%$ & \\
\hline \multirow[t]{2}{*}{ If yes, state the effects } & Fuel & - & $3(5.5 \%)$ & $3(16.7 \%)$ & 0.245 \\
\hline & Nil & $4(94.0 \%)$ & $5(89.0 \%)$ & $9(50.0 \%)$ & \\
\hline What do you know about Aromatic solvents & No knowledge & $50(100.0 \%)$ & $55(100.0 \%)$ & $55(100.0 \%)$ & - \\
\hline Inhale any of these chemicals while working? & Yes & $48(96.0 \%)$ & $51(92.7 \%)$ & $99(94.3 \%)$ & 0.521 \\
\hline Chemicals have direct contact with your skin? & Yes & $50(100.0 \%)$ & $55(100.0 \%)$ & $105(100 \%)$ & - \\
\hline \multirow[t]{2}{*}{ Do any periodic medical checkup? } & Yes & $10(20.0 \%)$ & $2(3.6 \%)$ & $12(11.4 \%)$ & 0.008 \\
\hline & $<1$ year & $6(60.0 \%)$ & - & $6(50.0 \%)$ & \\
\hline \multirow[t]{2}{*}{ If yes, when was the last time? } & $1-2$ years ago & $1(10.0 \%)$ & $2(100.0 \%)$ & $3(25.0 \%)$ & 0.027 \\
\hline & $2-3$ years ago & $3(30.0 \%)$ & - & $3(25.0 \%)$ & \\
\hline
\end{tabular}

$\mathrm{P}>005$ is insignificant at $95 \%$ confidence interval.

Only $13(26 \%)$ of 55 spray painters, $14(25.5 \%)$ of mechanics and $27(25.7 \%)$ of 105 (total) were aware of the ingredients of the chemicals they use.
Automobile spray painting and mechanical work are considered to be hard to do and are therefore meant for youths and young adults.

Table 3. Monthly Income.

\begin{tabular}{lll}
\hline Income & Frequency & Percent \\
\hline$<=5000$ & 48 & 45.7 \\
$5001-18000$ & 30 & 28.6 \\
$18001-30000$ & 15 & 14.3 \\
$30001-50000$ & 6 & 5.7 \\
$50001-100000$ & 6 & 5.7 \\
Total & 105 & 100.0 \\
\hline
\end{tabular}

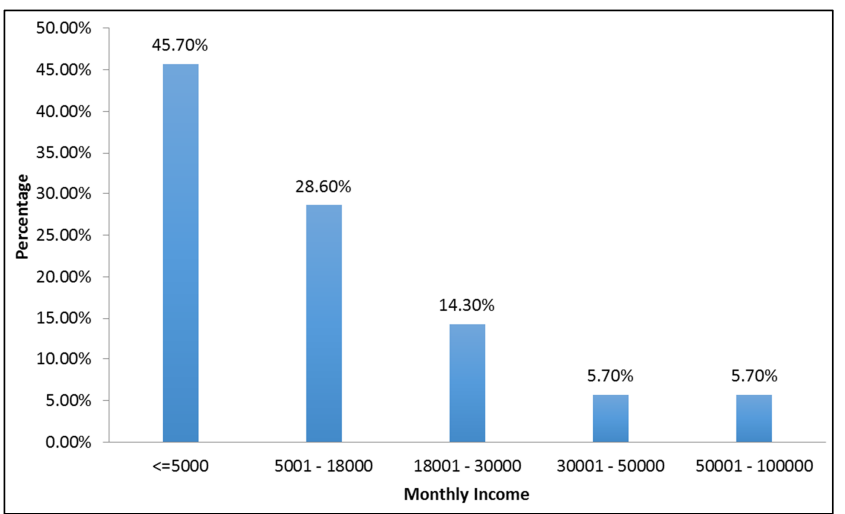

Figure 3. Monthly income. 

by Automobile Workers in North Bank, Makurdi Local Government, Makurdi, Benue State, Nigeria

Table 5. Knowledge about personal protective equipment.

\begin{tabular}{|c|c|c|c|c|c|}
\hline \multirow{3}{*}{ Question } & \multicolumn{5}{|l|}{ Occupation } \\
\hline & & Automobile Spray Painters & Mechanics & & \\
\hline & Response & Number (\%) & Number (\%) & Total (\%) & $\mathbf{p}$ \\
\hline \multirow{4}{*}{ What is personal protective equipment? } & Boots and Gloves & $11(22.0 \%)$ & $16(29.1 \%$ & $27(25.7 \%)$ & \multirow{4}{*}{0.682} \\
\hline & Used for protection & $5(10.0 \%)$ & $7(12.7 \%)$ & $12(11.4 \%)$ & \\
\hline & Nose Mask & $33(66.0 \%)$ & $30(54.5 \%)$ & $63(60.0 \%$ & \\
\hline & To prevent disease & $1(2.0 \%)$ & $2(3.6 \%)$ & $3(2.9 \%)$ & \\
\hline Wear personal protective equipment? & Yes & $21(42.0 \%)$ & $24(43.6 \%)$ & $45(42.9 \%)$ & 0.866 \\
\hline \multirow[t]{3}{*}{ You may/or have catarrh or cough? } & Yes & $26(52.0 \%)$ & $37(67.3 \%)$ & $63(60.0 \%)$ & \multirow[t]{3}{*}{0.111} \\
\hline & Can't remember & $10(38.5 \%)$ & $18(48.6 \%)$ & $28(26.7 \%)$ & \\
\hline & $<1 \mathrm{yr}$ & $2(7.7 \%)$ & $5(13.5 \%)$ & $7(6.7 \%)$ & \\
\hline \multirow[t]{3}{*}{ If yes, please state when this started? } & $4-5 y r s$ & - & $1(2.7 \%)$ & $1(1.0 \%)$ & \multirow[t]{3}{*}{0.200} \\
\hline & $>10 \mathrm{yrs}$ & $3(11.5 \%)$ & - & $3(2.9 \%)$ & \\
\hline & On and Off & $11(42.3 \%)$ & $13(35.1 \%)$ & $24(22.9 \%)$ & \\
\hline
\end{tabular}

$\mathrm{P}>005$ is insignificant at $95 \%$ confidence interval.

Most $63(60.0 \%)$ of the respondents defined personal protective equipment (PPE) as nose mask, $66 \%$ of spray printers and $54.5 \%$ of mechanics also called PPE nose mask.

Table 6. Knowledge, attitude and perception about occupational risk/hazard and safety measures.

\begin{tabular}{|c|c|c|c|c|}
\hline & Occupation $(\%$ mean \pm SD) & & & \\
\hline Parameter & Automobile Spray Painters $(\mathrm{n}=\mathbf{5 0})$ & Mechanics $(\mathbf{n}=\mathbf{5 5})$ & Total $(n=105)$ & $\mathbf{p}$ \\
\hline Knowledge of Occupational Hazard/Risk $\left(\mathrm{Q}_{23}-\mathrm{Q}_{29}\right)$ & $12.43 \pm 13.03$ & $14.81 \pm 14.52$ & $13.67 \pm 13.81$ & 0.381 \\
\hline Attitude towards risks/hazard $\left(\mathrm{Q}_{30}-\mathrm{Q}_{38}\right)$ & $25.25 \pm 18.91$ & $26.81 \pm 14.80$ & $26.07 \pm 16.81$ & 0.635 \\
\hline Perception of risk of occupational hazard $\left(\mathrm{Q}_{39-} \mathrm{Q}_{47}\right)$ & $13.33 \pm 11.70$ & $16.82 \pm 12.01$ & $15.16 \pm 11.94$ & 0.136 \\
\hline Safety measures (Q48 - Q55) & $30.75 \pm 24.12$ & $27.27 \pm 30.91$ & $28.92 \pm 27.81$ & 0.525 \\
\hline
\end{tabular}

$\mathrm{P}>005$ is insignificant at $95 \%$ confidence interval.

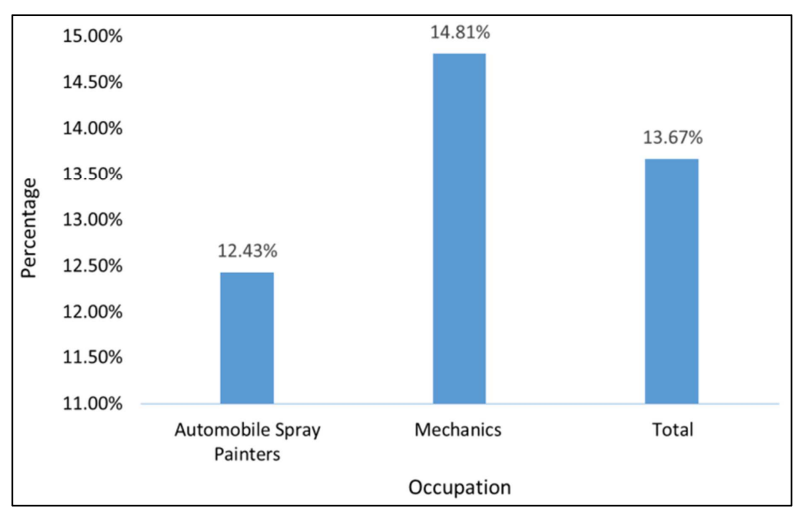

Figure 4. Knowledge of Occupational Hazard/Risk.

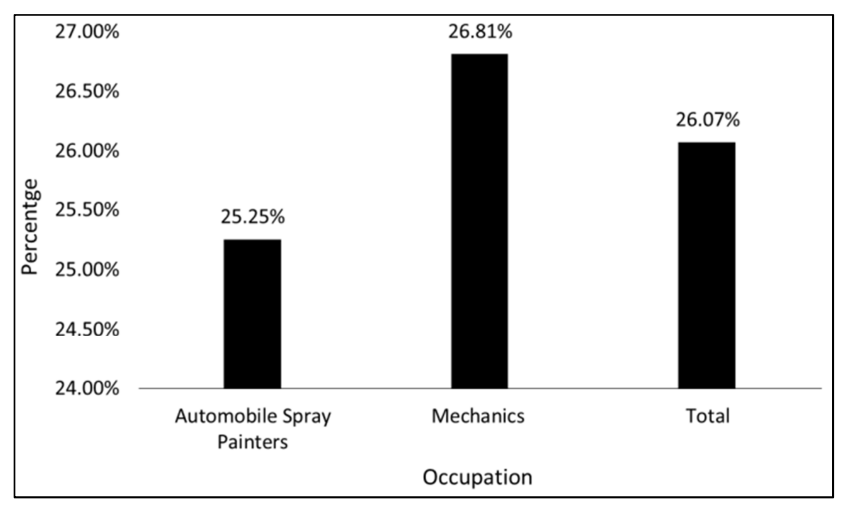

Figure 5. Attitude towards risks/hazard.

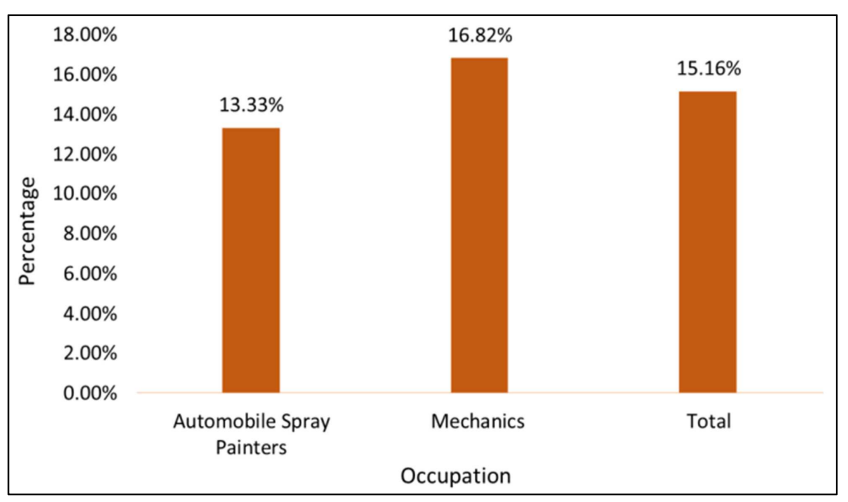

Figure 6. Perception of risk of occupational hazard.

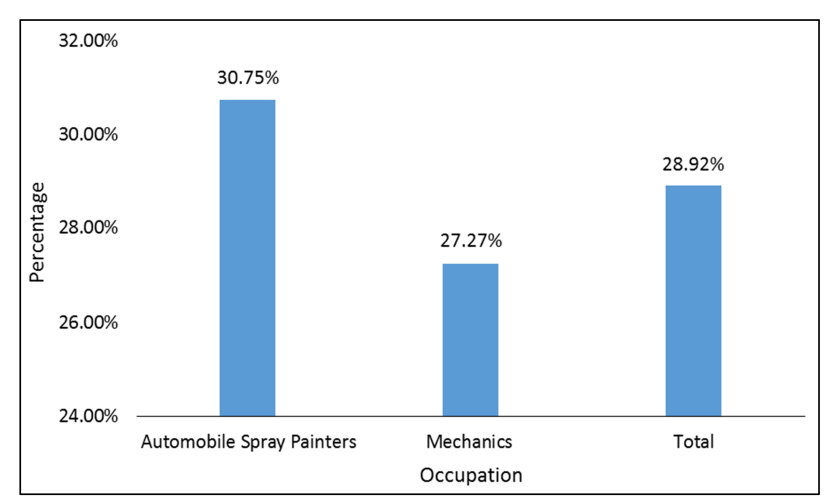

Figure 7. Safety measures. 
Table 7. Effect of education on Knowledge, attitude and perception about occupational risk/hazard and safety measures.

\begin{tabular}{|c|c|c|c|c|c|}
\hline Knowledge & Education & $\mathbf{N}$ & $\%$ Mean & Std. Deviation & $\mathbf{p}$ \\
\hline \multirow{5}{*}{ Knowledge of Occupational Hazard/Risk } & No formal Education & 51 & 23.11 & 12.74 & \multirow{5}{*}{$<0.001$} \\
\hline & Primary & 12 & 7.14 & 5.90 & \\
\hline & Secondary & 30 & 4.29 & 8.72 & \\
\hline & Diploma & 9 & 4.76 & 4.72 & \\
\hline & First degree & 3 & - & - & \\
\hline \multirow{5}{*}{ Attitude towards risks/hazard } & No formal Education & 51 & 37.01 & 14.85 & \multirow{5}{*}{$<0.001$} \\
\hline & Primary & 12 & 14.58 & 9.48 & \\
\hline & Secondary & 30 & 17.92 & 11.06 & \\
\hline & Diploma & 9 & 15.28 & 11.60 & \\
\hline & First degree & 3 & - & - & \\
\hline \multirow{5}{*}{ Perception of risk of occupation } & No formal Education & 51 & 20.59 & 10.67 & \multirow{5}{*}{$<0.001$} \\
\hline & Primary & 12 & 9.03 & 11.49 & \\
\hline & Secondary & 30 & 10.00 & 10.28 & \\
\hline & Diploma & 9 & 14.81 & 12.11 & \\
\hline & First degree & 3 & - & - & \\
\hline \multirow{5}{*}{ Safety measures } & No formal Education & 51 & 16.18 & 23.62 & \multirow{5}{*}{$<0.001$} \\
\hline & Primary & 12 & 40.63 & 28.27 & \\
\hline & Secondary & 30 & 46.25 & 25.46 & \\
\hline & Diploma & 9 & 20.83 & 22.53 & \\
\hline & First degree & 3 & 50.00 & - & \\
\hline
\end{tabular}

Most respondents did not have formal education, so it is not surprised seeing that they recorded higher knowledge of the first three questions.

\section{Discussion}

A total of One Hundred and Five (105) respondents were interviewed out of which One Hundred and five (105) questionnaires fully responded during the collection of data through were recovered giving a response rate of $100 \%$. Most of the respondents were married $81(77.1 \%)$, followed by1 8 (17.1\%) for single, $6(5.8 \%)$ for separated while none were divorced or widowed. There were $66(62.9 \%)$ Christians and 39 (37.1\%) Muslims. Sixty percent (62) of the respondents had their highest education level stopped at primary school with $51(48.6 \%)$ of no formal education and 12 (11.4\%) who had primary education. This is in agreement with study conducted by Agnes [10].

$30(28.6 \%)$ had secondary school certificates, $9(8.6 \%)$ had diploma out of which 8 where Auto mechanics and 1 was spray painter. There were $3(2.9 \%)$ respondents who had first degree of which 2 were automobile spray painters and one was an auto mechanic. None had MSc of PhD degrees. Most $78(74.5 \%)$ of the respondents had spent over 5 years in their current occupation, $21(20.0 \%)$ had been doing the work between $3-5$ years while few $6(5.7 \%)$ have spent not more than 2 years in the occupation.

The minimum age (in years) of the respondents was 19 and the maximum was 72 with the most frequent age being 35 while the median and the mean ages were 38 and $40 \pm 13$ respectively. The participants were all males because the occupations studied in this research are generally believed in Nigeria and in Africa to be for men only since they are considered to be hard and require a lot of energy.

Automobile spray painting and mechanical work are considered to be hard to do and are therefore meant for youths and young adults. The age category reflects this believe as the highest number of the respondents was seen in age group $31-40$ with 35 (33.3\%), followed by 25 (23.8\%) seen for age group $20-30$. These age groups are considered to be young adult and youth age groups respectively. Above 60 and below 20 age groups recorded smallest values of 9 $(8.6 \%)$ and $3(2.9 \%)$ respectively as the age groups considered to be either too old or too young to be active in such hard occupations. This is in agreement with study conducted by Odhiambo and Manda that many children from informal settlement areas drop out of school at an early age to seek employment due to poverty [11].

Only $13(26 \%)$ of 55 spray painters, $14(25.5 \%)$ of mechanics and $27(25.7 \%)$ of 105 (total) were aware of the ingredients of the chemicals they use. Just $18(17.1 \%)$ of the 105 respondents of which 11 were mechanics and 7 spray painters knew the effects of the chemicals they use. This is in an agreement with the study conducted by Lansink [12]. This probably is due to proximity of spreader to spray painter's face (Breathing zone of spray painter).

Fifty percent (9) of those who believed they had the knowledge of the effects of these chemical components could not mention a particular effect while $6(33.3 \%)$ believed they could result to cough. None of the respondents had any knowledge about aromatic solvents. Most 99 (94.3\%) of the respondents of which 48 (96\% of 50) were spray painters and $51(92.7 \%$ of 55$)$ admitted that they regularly inhale chemical while working while all respondents admitted regular chemical contact of their skin with effect on emission of paint onto the skin and outer clothing, this is line with study conducted by Lansink [12]. Yet, only 12 (11.4\%) have ever done periodical medical checkup 10 of which were spray painters with only 2 mechanics. Fifty percent (6) of those who have engaged in periodic medical checkup had their checkups done within one year before interview while another $50 \%$ had theirs between $1-3$ years before the time of 
interview. The $\mathrm{p}$ value for each of the tested parameter $(>0.05)$ shows clearly that there is no significant difference in the knowledge of both the Automobile spray printer and the Mechanics.

Most $63(60.0 \%)$ of the respondents defined personal protective equipment (PPE) as nose mask, 66\% of spray printers and $54.5 \%$ of mechanics also called PPE nose mask. 27 (25.7\%) believed that PPEs are either boots or gloves for protecting hands and legs, $12(11.4 \%)$ called PPEs anything used to protect any part of the body while $3(2.9 \%)$ defined it as what is used to prevent diseases. Only 45 (42.9\%) of 105 respondents admitted wearing PPE while working, 63 (60\%) admitted having catarrh or may have it. Among the 63 who had catarrh, 28 (26.7\%) couldn't remember when it started, 7 $(6.7 \%)$ said it started in less than a year, $3(2.9 \%)$ for more than 10 years and $1(1.0 \%)$ between 4 to 5 years before the interview while $24(22.9 \%)$ were experiencing on and off catarrh. This is line with the study conducted by NIOSH., 1978 [9], Charles stated that Workers exposed to high concentrations of diisocyanates may result in what is called chemical bronchitis, chest tightness, nocturnal dyspnea (shortness of breath), pulmonary edema (fluid in the lungs) and reduced lung function)[13]. It is also known that lung functions decrease with number of exposures [14]. Sensitization of isocyanate can happen even within days of exposure [15]. According to the study, the spray painters had multiple symptoms of the disease associated with spray painting.

However, there is no statistical significant difference in the knowledge of spray painters and mechanics about PPE as it can be generally rated poor $(<50 \%), P>0.05$. The knowledge and perception of both spray painters and mechanics about occupational health hazards are generally low (below 20\%). Their attitudes towards occupational health hazards are also rated very poor (below 30\%) and safety measures are low for both. However, none of the two groups can be rated better than the other $(p>0.05)$. Most respondents did not have formal education, so it is not surprised seeing that they recorded higher knowledge of the first three questions. Presence of disease symptoms associated with spray painting can be caused by many factors, both external such as poverty to political good will and other internal factors such as level of education, to lack of training in basics relevant skills in paint technology, lack of use of personal protective equipment and other infrastructures like enclosed buildings [11]. The study suggested that there is a significant difference in the knowledge, attitude, perception of spray painters and mechanics based on their level of education. This same effect is seen in safety measures $(p<0.05)$.

\section{Conclusion}

The results from this study showed that knowledge of potential occupational hazards among automobile workers was generally low (below 20\%). Equally their attitudes towards occupational health hazards are also rated very poor (below 30\%) and safety measures are low for both automobile workers used for this study. However, safety practice among automobile workers is poor irrespective of educational status or occupational category.

The population at risk of ill health effects of spray paint exposure was young people. It was observed that spray painters in the study were using little or no form of protection while engaged in spray painting activities and concluded that, this lack of protection was increasing exposure time (actual time in contact with auto paint), which increased the likelihood of contracting disease symptoms associated with spray painting. The study also revealed that spray painters in small scale informal auto garages in North Bank Mechanic village had poor health seeking behaviors. According to the study, they rarely consulted a health professional or visit health facilities when suffering from the diseases symptoms associated with spray painting activities.

\section{Recommendations}

1. There is need for regular training on safety guidelines and enforcement of standard/universal safety practices by automobile workers so as to reduce potential occupational hazards.

2. Automobile garages should provide appropriate equipment necessary for automobile workers to carry out their duties.

3. As a matter of fact, public awareness and preventive programs to be carried out in the workplaces where spray painting is done with supports of policy makers.

4. There should be a development of training manuals and programmes for spray painters and automobile mechanics and other operators in small scale garages so as to ensure some competence in the industry.

5. There should be a periodical monitoring and evaluation of health of all the workers in the auto garages and paint industries in Nigeria and other developing countries as these health hazards cuts across all the stages of manufacture, storage and handling, and end use of the auto paint and allied chemicals [16].

6. The policy makers should also organize social development by protecting the most vulnerable young people who are the majority in the industry and are integral part of the future intellectual, social and key to Nigeria largest economic in Africa by developing standards and other regulatory procedures for the industry

\section{References}

[1] Gomes, J., Lloyd, O., \& Norman, J. (2001). Dust exposure and impairment of lung functions at a small iron foundry in a rapidly growing country: Journal of Occupational and Environmental Medicine Vol. 58 656-662.

[2] Kenya National Bureau of Statistics (KNBS) [2003]. Kenya National Bureau of Statistics: Statistical Survey, Nairobi. 
[3] Africa Regional office (DES/AFRO) [2001]. Occupational Health and safety Services in the Africa Region: Situational analysis, Brazzaville, Regional Office for Africa. Division for Health, Environment and Sustainable Development, unpublished Report; 8-17.

[4] Udonwa E. (2008). Exposure of petrol station attendants and auto mechanics to premium motor sprit fumes in calabar, Nigeria. Journal of Environmental and Public Health Volume 2008.

[5] Williams, Pamela R.; Panko, Julie M.; Unice, Ken; Brown, Jay L.; and Paustenbach, Dennis J. (2011) "Occupational Exposures Associated with Petroleum-Derived Products Containing Trace Levels of Benzene." Journal of Occupational and Environmental Hygiene. 5: 565-574.

[6] Spencer, John W. and Plisko, Marc J. (2007) “A Comparison Study Using a Mathematical Model and Actual Exposure Monitoring for Estimating Solvent Exposures During the Disassembly of Metal Parts." Journal of Occupational and Environmental Hygiene. 4: 4, 253-259.

[7] Stidham, Todd ASE. Chilton's Ford Ranger/Explorer/Mountaineer 1991-99 Repair Manual. Haynes North America Inc. 1999.

[8] Daniell, William; Stebbins, Arlene; Kalman, David; O'Donnell, James F.; and Horstman, Sandford W. (2010) "The Contributions to Solvent Uptake by Skin and Inhalation Exposure.” American Industrial Hygiene Association Journal. 53: $2,124-129$.

[9] National Institute for Occupational Safety and Health (1978). Criteria for Recommended Standard; Occupational exposure to diisocyanates. Cincinnati Ohio, United States of America. Department of Health, Education, Welfare, Public Health Service, Centre for Disease Control.

[10] Agnes K. Mwatu (2011) Health Hazards Associated with Spray Painting Among Workers In Small ScaleAuto Garages In Embakasi Division, Nairobi, Kenya. Thesis Submitted in Partial Fulfillment of the requirements for the award of Degree of Master in Public Health (MPH) in the School of Health Sciences of Kenyatta University.

[11] Odhiambo, W. \& Manda, D. R. (2003). Urban Poverty and Labour Force participation in Kenya.

[12] Lansink, C. J. M., Van Hengstum, C. \& Brouwer, D. H. (1997). Dermal exposure due to airless spraying; Report V97. 1057. Nutrition and Food Research Institute. Zeist, Netherlands.

[13] Charles, J., Bernstein, A., Jones, B., Jones, D., Edward, J., Seal, R., \&Seaton, A (1976). Hypersensitivity pneumonitis after exposure to isocyanates. Thorax 31: 127-136.

[14] Turnlinng. G., Alexander, F. Hedenstierna, R. \& Plato, N. (1990). Decreased lung function and exposure to diisocyanates [HDI and HDI-BT] in car repair painters; Observation of re-examination 6 years after initial study. Journal of Industrial Medicines 17\{3\}: 229-130.

[15] Dillon (2000). Safe Work Procedures for isocyanatesCompany Procedures.

[16] Ontario Ministry of Labour. (1987). Designated Substance in Workplace: A Guide to Isocyanates Regulation. (1987, September) 28-33. 